\title{
INCIDÊNCIA DE Listeria monocytogenes EM ALIMENTOS
}

\author{
K. I. SILVÉRIO ${ }^{1}$, G. G. PIERETTi ${ }^{1}$, J. L. ANTIGO ${ }^{1}$, L. A. C. TONON ${ }^{2}$, J. G. MIKCHA ${ }^{3}$, \\ G. S. MADRONA ${ }^{2}$ \\ ${ }^{1}$ Universidade Estadual de Maringá, Centro de Ciências Agrárias \\ ${ }^{2}$ Universidade Estadual de Maringá, Departamento de Engenharia de Alimentos \\ ${ }^{3}$ Universidade Estadual de Maringá, Departamento de Biologia Celular \\ E-mail para contato: gsmadrona@uem.br
}

\begin{abstract}
RESUMO - O presente trabalho teve como objetivo analisar a incidência de Listeria monocytogenes em produtos de origem animal. Foram analisadas 2569 amostras, que incluíam queijos, frangos, suínos, bovinos, embutidos, peixes e swabs. L. monocytogenes foi identificada em 40 amostras, sendo a maior incidência observada para frangos com 21 amostras presentes e depois queijos com 8 amostras presentes. Para as demais amostras ausentes para L. monocytogenes, 145 amostras foram presentes para outras espécies de Listeria sp. De acordo com os dados apresentados, pode-se concluir que, embora a prevalência de L. monocytogenes tenha sido de 1,5\%, a ocorrência de $5,7 \%$ de contaminação por outras espécies de Listeria sp. pode ser um indicativo de que as indústrias de alimentos ainda apresentam dificuldades no controle desse patógeno, sendo necessária a readequação nas práticas de limpeza e sanificação das plantas de processamento para redução da contaminação dos alimentos e prevenção da listeriose.
\end{abstract}

\section{INTRODUÇÃO}

Devido a exigências do mercado consumidor de alimentos, o controle da qualidade tem tornado-se mais rigoroso, evidenciando a contaminação microbiológica nos processos de manipulação, industrialização e armazenamento. Esse aumento pode ser demonstrado na procura da análise de Listeria monocytogenes em produtos de origem animal, acabados ou in natura (SILVA, VILARDI e TIBANA, 1998).

A relevância da L. monocytogenes em Saúde Pública diz respeito, de um lado, à gravidade da manifestação clínica, resultante do comprometimento do sistema nervoso central, e do outro, à possibilidade da infecção acometer preferencialmente as gestantes, com sérias consequências para os fetos (GERMANO e GERMANO, 2003). Inquestionavelmente patogênica para o homem, $\mathrm{e}$, diferente da maioria dos patógenos de origem alimentar que geralmente provocam sintomas gastrointestinais, a listeriose se manifesta clinicamente com semelhança a um resfriado, com febre baixa e mal estar geral, podendo progredir para meningite, meningoencefalite, septicemia, aborto ou parto prematuro (JARADAT, SCHUTZE e BHUNIA 2001; SILVA, JUNQUEIRA e SILVEIRA, 1997). Sendo os grupos mais susceptíveis representados por gestantes, neonatos, bebês, idosos e indivíduos com o sistema imunológico comprometido (LEITE et al., 2002). 
L. monocytogenes tem sido isolada a partir de uma grande variedade de produtos alimentares, crus ou processados, tanto de origem animal, como de origem vegetal e, sendo o ambiente um importante reservatório, não é de se surpreender que este micro-organismo aceda facilmente aos produtos alimentares (GUERRA e BERNARDO, 2004).

Diferentes estudos identificaram a presença de Listeria monocytogenes numa grande diversidade de alimentos, como carnes de bovinos, de suínos e de aves, leite e derivados, pescados, vegetais, alimentos embutidos e produtos diversos prontos para o consumo e refrigerados (SANTOS et al., 2004). A maior importância da L. monocytogenes para a indústria de alimentos talvez seja o fato desta bactéria poder sobreviver e se multiplicar em temperatura de refrigeração. Este fator constitui num obstáculo para a maioria dos patógenos. Esse dado é relevante principalmente para os alimentos refrigerados prontos para consumo em caso de serem insuficientemente processados e/ou contaminados após o processamento (MCCARTHY, 1997).

O Departamento de Agricultura dos Estados Unidos (USDA) lançou a Política de Tolerância Zero que determina a ausência do L. monocytogenes patógeno em $25 \mathrm{~g} / \mathrm{mL}$ de amostra (UNITED STATES, 2006). Alguns países da Europa são mais tolerantes, admitindo a presença de até 100 células de L. monocytogenes por grama ou por mililitro de alimento (ARCHER, 1996).

A Legislação Brasileira não prevê limites de tolerância para a presença do microrganismo em carnes e produtos cárneos. A Resolução da Diretoria Colegiada, da Agência Nacional de Vigilância Sanitária (ANVISA - RDC no 12 de Janeiro de 2001) aprovou o Regulamento Técnico sobre Padrões Microbiológicos para Alimentos e somente estabeleceu a pesquisa de $L$. monocytogenes (ausência em $25 \mathrm{~g}$ ) para queijos de média, alta e muito alta umidade (BRASIL, 2014). Para outros produtos de origem animal não há padrão estabelecido.

Neste contexto, o presente trabalho teve como objetivo avaliar a incidência de $L$. monocytogenes em produtos de origem animal, avaliando matérias primas destinadas ao processamento nas indústrias alimentícias e produtos prontos destinados ao consumidor final, visando disponibilizar dados sobre a ocorrência desse patógeno e sua importância para a saúde pública.

\section{MATERIAL E METÓDOS}

Foram analisadas 2309 amostras comerciais de diferentes marcas provenientes dos Estados do Paraná, Santa Catarina e São Paulo. Foram obtidas amostras de queijos (minas e mussarela), frangos (corte e carcaça), suínos (corte), bovinos (corte e carcaça), embutidos (variados) e peixes. As análises bacteriológicas foram realizadas no laboratório de análise de alimentos e água, credenciado pelo Ministério da Agricultura, Pecuária e Abastecimento (MAPA, 2014) e habilitado pela REBLAS/ANVISA localizado na cidade de Maringá, PR., os produtos foram mantidos sob refrigeração até o momento da análise. Realizou-se o isolamento e a identificação bioquímica das bactérias do gênero Listeria. segundo metodologia preconizada pelo MAPA, pela Normativa SDA N ${ }^{\circ} 62$ de 26 de agosto de 2003.

$\mathrm{O}$ enriquecimento seletivo foi realizado em duas etapas. Na primeira etapa $25 \pm 0,2 \mathrm{~g} / \mathrm{mL}$ foram homogeneizadas em $225 \mathrm{~mL}$ de caldo UVM (Difco) e incubadas a $30 \pm 1^{\circ} \mathrm{C}$ por 24 horas. 


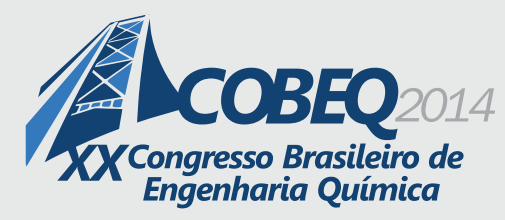

$\mathrm{Na}$ segunda etapa, após o período de incubação, foram transferidos $0,1 \mathrm{~mL}$ da cultura inicial para Caldo Fraser (Difco) suplementado com citrato de amônio e ferro III que foi incubado a $30 \pm 1{ }^{\circ} \mathrm{C}$ por 24 a 48 horas.

Após o enriquecimento seletivo as amostras de produtos cárneos foram semeadas em ágar triptose com ácido nalidíxico (ATN - Difco) e ágar Palcam (AP - Difco) e as amostras de produtos lácteos foram semeadas em ágar Oxford suplementado (AO - Difco) e ágar Palcam suplementado (AP - Difco). As placas de ATN foram incubadas a $30 \pm 1{ }^{\circ} \mathrm{C}$ por 24 horas e as placas de AP e AO na mesma temperatura, por 24 a 48 horas.

Três colônias típicas de cada amostra foram semeadas em ágar Estoque (Difco) sendo incubadas a $30 \pm 1{ }^{\circ} \mathrm{C}$ por 24 horas. A partir das colônias isoladas em ágar estoque inclinado, foram realizadas a coloração de Gram e as provas bioquímicas de catalase, motilidade, redução de nitrato, produção de $\alpha$-hemólise e fermentação de carboidratos.

Para a identificação de L. monocytogenes o utilizou-se o Kit de Identificação API LISTERIA (BioMérieux) sendo utilizado como controle positivo a cepa L. monocytogenes, ATCC 7644.

\section{RESULTADOS DISCUSSÃO}

Das 2309 amostras analisadas, de produtos acabados e "in natura", 132 (5,72 \%) apresentaram contaminação por Listeria spp sendo 38 (1,65\%) positivas para L. monocytogenes. A relação de cepas dos diferentes sorotipos isolados para frango (carcaça e corte), suínos (corte), embutidos (variados) e bovinos (carcaça e corte) estão apresentadas na Tabela 1.

Tabela 1 - Ocorrência de Listeria monocytogenes e Listeria spp. em amostras de frangos, suínos,

embutidos e bovinos

\begin{tabular}{l|cccccccc}
\hline $\begin{array}{l}\text { Espécie de } \\
\text { Listeria }\end{array}$ & Frango & $\begin{array}{c}\text { \% por } \\
\text { espécie }\end{array}$ & Suíno & $\begin{array}{c}\% \text { por } \\
\text { espécie }\end{array}$ & Embutido & $\begin{array}{c}\% \text { por } \\
\text { espécie }\end{array}$ & Bovino & $\begin{array}{c}\% \text { por } \\
\text { espécie }\end{array}$ \\
\hline $\begin{array}{l}\text { L. } \\
\text { monocytogenes }\end{array}$ & 21 & $2,8 \%$ & 4 & $3,6 \%$ & 4 & $3,3 \%$ & 0 & $0,0 \%$ \\
$\begin{array}{l}\text { L. welshimeri } \\
\text { L. grayi }\end{array}$ & 23 & $3,1 \%$ & 3 & $2,8 \%$ & 4 & $3,5 \%$ & 5 & $5,2 \%$ \\
$\begin{array}{l}\text { L. innocua } \\
\text { L. ivanovii }\end{array}$ & 4 & $1,3 \%$ & 4 & $3,7 \%$ & 4 & $3,5 \%$ & 0 & $0,0 \%$ \\
$\begin{array}{l}\text { L. seeligeri } \\
\text { Total Listeria }\end{array}$ & 1 & $0,5 \%$ & 1 & $0,9 \%$ & 1 & $0,8 \%$ & 3 & $3,1 \%$ \\
spp. & $0,2 \%$ & 0 & $0,0 \%$ & 0 & $0,0 \%$ & 0 & $0,0 \%$ \\
\hline $\begin{array}{l}\text { Total de } \\
\text { Amostras }\end{array}$ & 70 & $5,5 \%$ & 9 & $8,4 \%$ & 9 & $7,8 \%$ & 9 & $9,4 \%$ \\
\hline
\end{tabular}

A Tabela 2 apresenta os resultados para as amostras de queijo e peixe avaliadas. 
Tabela 2 - Ocorrência de L. monocytogenes e Listeria spp. em amostras de queijos e peixe

\begin{tabular}{l|cccc}
\hline Espécie de Listeria & Queijo & \% por espécie & Peixe & \% por espécie \\
& & & & \\
\hline L. monocytogenes & 8 & $0,7 \%$ & 1 & $2,7 \%$ \\
L. welshimeri & 9 & $0,7 \%$ & 1 & $2,8 \%$ \\
L. grayi & 23 & $1,9 \%$ & 3 & $8,3 \%$ \\
L. innocua & 12 & $1,0 \%$ & 0 & $0,0 \%$ \\
L. ivanovii & 7 & $0,6 \%$ & 0 & $0,0 \%$ \\
L. seeligeri & 9 & $0,7 \%$ & 1 & $2,8 \%$ \\
Total Listeria spp. & 60 & $5,0 \%$ & 5 & $13,9 \%$ \\
\hline Total de amostras & 1202 & & 37 & \\
\hline
\end{tabular}

A maior ocorrência de contaminação por L. monocytogenes se deu em amostras de suínos (cortes) L. monocytogenes foi identificada em 4 amostras $(3,6 \%)$ das 111 analisadas, resultado este similar ao encontrado para embutidos, para o total de 119 amostras testadas, $L$. monocytogenes foi presente em 4 amostras $(3,3 \%)$ e para frangos (carcaças e cortes) das 745 amostras analisadas, 21 amostras $(2,8 \%)$ apresentaram L. monocytogenes. Para as amostras de carne bovina (cortes e carcaças) analisadas, L. monocytogenes não foi detectada em nenhuma das 95 amostras analisadas.

Em queijos L. monocytogenes foi identificada em $8(0,7 \%)$ das 1202 amostras analisadas. Para as amostras de peixe analisadas, L. monocytogenes foi identificada em uma amostra $(2,7 \%)$ das 37 analisadas.

Pode-se observar que L. monocytogenes foi isolada em vários tipos de alimentos devendo ser ressaltado que alguns destes são produtos prontos para o consumo, não sendo submetidos a tratamentos térmicos, e mantidos sob temperaturas de refrigeração, propiciando condições necessárias para o desenvolvimento de L. monocytogenes.

Devido à alta ocorrência de L. monocytogenes em aves, e também por ser esta uma das fontes de proteína animal de baixo custo utilizada pelo homem, as aves tem merecido atenção especial por parte de alguns pesquisadores. É de suma importância alertar para o aumento de contaminação desse produto, podendo ser atribuído principalmente ao processo de abate das aves, onde a Listeria spp. pode estar presente nas fezes desses animais e também nas águas dos chillers, gerando a contaminação cruzada dos alimentos.

De acordo com Kamat e Nair (1996), L. innocua pode ser um organismo ideal e seguro como um marcador de $L$. monocytogenes em indústrias alimentícias, visto que este exibe a maioria das características da L. monocytogenes, com exceção da não produção de hemolisina e da apatogenicidade. Isto possibilita o uso de L. innocua como um indicador biológico para verificar a eficiência destes tratamentos, efetuados durante o processamento de produtos cárneos. No presente estudo, a maior ocorrência de L. innocua nas amostras de queijos corrobora com os resultados encontrados por Petran e Swanson (1993).

Das 60 amostras de queijos 8 apresentaram contaminação por L. monocytogenes (Tabela 2). Dentre os produtos lácteos, os queijos são os mais comumente contaminados por essa bactéria (BORGES, 2009), segundo o autor esta contaminação está associada principalmente ao leite 


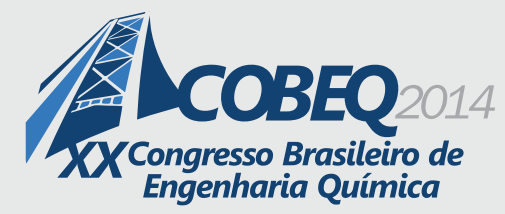

19 a 22 de outubro de 2014

Florianópolis/SC

usado na fabricação ou ao ambiente de processamento. No Brasil, L. monocytogenes foi encontrada em $50 \%$ das amostras de leite cru e em 16,7\% das amostras de leite pasteurizado e em $25 \%$ dos tubos de borracha utilizados para transportar o soro (GUERRA e BERNARDO, 2004).

A menor ocorrência de cepas isoladas de L. monocytogenes em carne suína, embutidos e peixes foi também constatada por Santos et al (2005) isolando este micro-organismo em apenas uma amostra e Bersot et al. (2001) que também encontraram um baixo percentual deste microorganismo em 26,0 \% das 30 amostras de mortadela analisadas. Nihal (2010) isolou $L$. monocytogenes em $44,5 \%$ das 30 amostras de peixes de água doce analisadas e César (2008), isolou L. monocytogenes em 3 das 76 amostras de swabs de superfície coletados em industrias produtoras de salsicha.

Não foi identificada a presença do patógeno em amostras de carne bovina, em contrapartida, Vitas, Aguado e Garciajalon (2004) isolaram L. monocytogenes em 103 das 295 amostras de carne bovina crua analisadas.

No que diz respeito à incidência das espécies Listeria, Listeria welshinerie seguida por $L$. grayi e L. monocytogenes foram isoladas com maior freqüência.

\section{CONCLUSÕES}

De acordo com os dados obtidos nesse trabalho, pode-se concluir que em geral encontraram-se baixos valores de ocorrência de L. monocytogenes, sendo a maior ocorrência de 3,6\% para suínos e a menor para bovinos $(0 \%)$. Conclui-se que indústria de alimentos ainda apresenta dificuldades no controle desse patógeno, sendo necessária a readequação nas práticas de limpeza e sanitização das plantas de processamento para redução da contaminação dos alimentos e prevenção da listeriose.

\section{REFERÊNCIAS}

ARCHER DL. Listeria monocytogenes: the science and policy. Foo. Cont. v. 7, n.4, p. 181-200, 1996.

BERSOT LS; LANDGRAF M; FRANCO DDG; DESTRO MT. Production of mortadella: behavior of L. monocytogenes during processing and storage conditions. Mea. Sci. v. 57, p. 19$26,2001$.

BORGES MF. Listeria monocytogenes em leite e produtos lácteos - Fortaleza: Embrapa Agroindústria Tropical; 2009.

BRASIL, Ministério da Agricultura, Pecuária e Abastecimento. Secretaria de Defesa Agropecuária - MAPA/DAS. IN No 62 de 26 de Agosto de 2003. Oficializa os métodos analíticos oficiais para análises microbiológicas para controle de produtos de origem animal e água. Disponível em http://extranet.agricultura.gov.br/sislegisconsulta/consultarLegislacao.do?operacao=visualizar\&id=2851. Acesso em: 20 janeiro de 2014. 
BRASIL. ANVISA - Agência Nacional de Vigilância Sanitária. Resolução - RDC no. 12, de 02 de Janeiro de 2001 - Regulamento Técnico sobre os padrões microbiológicos para alimentos. Disponível em http://www.anvisa.gov.br/legis/resol/12 01rdc.htm. Acesso em: 20 de janeiro de 2014.

CESAR APR. Listeria spp. e Listeria monocytogenes na produção de salsichas tipo Hot Dog e hábitos de consumo. Goiânia: Universidade Federal de Goiás; 2008.

GERMANO PML; GERMANO MIS. Higiene e vigilância sanitária de alimentos. São Paulo: Varela; 2003.

GUERRA MM; BERNARDO FA. Fontes de contaminação dos alimentos por Listeria monocytogenes. Hig. Alim., v. 18, n. 120, p.12-8, 2004.

JARADAT ZW; SCHUTZE GE; BHUNIA AK. Genetic homogeneity among Listeria monocytogenes strains from infected patients and meta products from two geographic locations determined by phenotyping, ribotyping and PCR analysis of virulence genes. Int. J. Food Microb. v. 76, p.1-10, 2001.

KAMAT, A. S.; NAIR, P. M. Identification of Listeria innocua as a Biological indicator for inactivation of L. monocytogenes by some meat processing treatments. Leb.-Wissu-Tech., v. 29, p. 714-720, 1996.

LEITE CC; GUIMARÃES AG; RIBEIRO NS; ASSIS PN. Pesquisa de Listeria monocytogenes e Escherichia coli em queijo do tipo "coalho" comercializado em Salvador. Rev Anal v. 2, n. 1 p.38-41, 2002.

MCCARTHY SA. Incidence and survival of Listeria monocytogenes in ready-to-eat seafood products. J Food Prot. v. 60, n. 4, p. 372-376, 1997.

NIHAL Y. Prevalence of Listeria, Aeromonas, and Vibrio species in fish used for human consumption in Turkey. J Food Prot. v. 73, n. 2, p. 380-385, 2010.

PETRAN, R. L.; SWANSON, K. M. J. Simultaneous Growth of Listeria monocytogenes and Listeria innocua. J Food Prot., v. 56, n. 7, p. 616-618, 1993.

SANTOS LAG; PINTO PSA; MORAES MP; VANETTI MCD; BEVILACQUA PD; PINTO MS. Detecção de Listeria monocytogenes como subsidio a determinação de pontos críticos de controle no abate de suínos. Biocie. J v. 21, n.2, p. 131-135, 2005.

SANTOS LAG; TEODORO VAM; MONTEIRO LL; GUIMARÃES KR; PINTO PSA; BEVILACQUA PD. Listeriose transmissível por produtos de origem animal. Hig. Alim. v. 18, n. 124, p. 35-42, 2004. 
SILVA MCD; VILARDI TCC, TIBANA A. Avaliação de métodos para a detecção de Listeria em queijos. Ciên. e Tec. Alim. v. 18, n. 2, p.150-155,1998.

SILVA N; JUNQUEIRA VCA; SILVEIRA NFA. Manual de métodos de análise microbiológica de alimentos. São Paulo: Varela; 1997.

United States. Departamento of Agriculture. Food Safety and Inspection Service. Science Laboratories e Procedures. Guide books e Methods. Microbiology laboratory Guidebook Isolation and identification of Listeria monocytogenes from read meat, poultry, egg and environmental samples. 8.05. Disponível em: www.usda.gov. Acesso em: 16 de dezembro de 2006.

VITAS AI; AGUADO V; GARCIAJALON I. Occurrence of Listeria monocytogenes in fresh and processed foods in Navarra (Spain). Int. J Foo. Microb., v. 90, n.1, p. 349-356, 2004. 